\title{
FENOLOGIA DA ACEROLEIRA CV. OLIVIER EM JUNQUEIRÓPOLIS-SP ${ }^{1}$
}

\author{
ELISA ADRIANO ${ }^{2} \&$ SARITA LEONEL ${ }^{3}$
}

RESUMO-A aceroleira é uma planta de clima tropical que produz frutos muito ricos em vitamina C. Apesar de ser amplamente difundida, são poucos os trabalhos realizados com essa cultura no País. O presente trabalho objetivou avaliar a fenologia e o crescimento dos frutos da aceroleira cv. Olivier em duas épocas. Para tanto, foi implantado um experimento em pomar comercial no município de Junqueirópolis-SP. Foram avaliados dois ciclos reprodutivos: setembro de 2009 e janeiro de 2010, sendo que, em cada época, foram marcados 400 botões florais distribuídos em 10 plantas. Para avaliação fenológica, o ciclo foi dividido em estádios, sendo avaliados a duração destes, do ciclo reprodutivo, a taxa de frutificação efetiva e o crescimento dos frutos. A duração dos estádios e do ciclo reprodutivo, a taxa de frutificação efetiva e o crescimento dos frutos foram influenciados pelo fator época, sendo que, no mês de janeiro, a duração dos estádios fenológicos foi menor, resultando no desenvolvimento mais rápido dos frutos, que também apresentaram maior diâmetro. Porém, no que se refere à taxa de frutificação, a época de setembro apresentou maior fixação dos frutos. Também foi verificado que o maior índice de abortamento se deu no estádio de perda de pétala em ambas as avaliações. Apesar da diferença na velocidade de crescimento e tamanho dos frutos, ambas as épocas apresentaram crescimento mais acentuado nos primeiros oito dias, mostrando-se linear no restante do ciclo. Termos para indexação: acerola, florescimento, frutificação, Malpighia emarginata DC.

\section{PHENOLOGY OF BARBADOS CHERRY TREES CV. OLIVIER, IN JUNQUEIRÓPOLIS/SP}

\begin{abstract}
The Barbados cherry tree is a tropical plant which produces fruits rich in vitamin C. It is a widespread crop in Brazil, however, there are few studies concerning its knowledge. The present study aimed to evaluate the reproductive phenology and growth of fruit of Barbados cherry tree cv. Olivier at different times. The experiment was set up at the city of Junqueirópolis-SP. Two reproductive cycles were evaluates, September 2009 and January 2010, and in each time 400 buds which were distributed among 10 plants were scored. The phenological cycle was divided in different phenological stages which were evaluated according to the duration of each stage, cycle, rate of fruit set and fruit growth. The duration of the stages, the reproductive cycle, the fruit set rate and fruit growth were influenced by the month (period) considered. In January the duration of phenological stages was shorter, resulting in more rapid development of fruits which also reached a greater diameter. However, concerning to the fruitage rate September month showed a higher fruit set. It was also found that the highest rate of abortion occurred at the stage of petal loss in both evaluations. Despite the difference in fruit growing rate and fruit size both times showed faster growth in the first eight days, and a more linear growth in the remainder of the cycle.
\end{abstract}

Index terms: Barbados cherry, flowering rate, fruit rate, Malpighia emarginata DC.

\section{INTRODUÇÃO}

O Brasil é o terceiro maior produtor mundial de frutas, atrás apenas da China e Índia, tendo exportado 759,4 milhões de toneladas em 2010 , com previsão de aumento nas exportações em $25 \%$ nos próximos quatro anos (PORTAL DO AGRONEGÓCIO, 2011).

Dentre as frutas produzidas no Brasil, a acerola (Malphigia emarginata DC.) vem ganhando cada vez mais espaço no mercado, devido ao seu elevado teor de vitamina C. Trata-se de uma planta de clima tropical com origem no norte da América do Sul, América Central e ilhas do Caribe (JUNQUEIRA et al., 2004).

Por ser uma planta bastante exigente em luz e calor, os aspectos fenológicos e produtivos da acerola podem variar de estação para estação, de um ano para outro e também de acordo com a região onde é cultivada. O ciclo reprodutivo muito curto é bastante

'(Trabalho 013-12). Recebido em: 03-01-2012. Aceito para publicação em: 09-05-2012.

${ }^{2}$ Doutoranda em Agronomia - Horticultura, Departamento de Produção Vegetal, FCA/UNESP, Botucatu- SP, Fazenda Lageado, Botucatu-SP, CEP: 18610-000. E-mail: elisaadrianojd@hotmail.com

${ }^{3}$ Professor Adjunto, Departamento de Produção Vegetal, FCA/UNESP, Botucatu- SP. E-mail: sarinel@fca.unesp.br 
vulnerável a variações climáticas, que podem alterar a duração dos estádios fenológicos e influenciar na produção (CARPENTIERE-PÍPOLO et al., 2008).

A produção da aceroleira tem início um ano após o plantio, quando se usam mudas obtidas por estaquia, e 2,5 anos, quando as mudas são produzidas por sementes. Ocorrem em geral quatro períodos de frutificação durante o ano, podendo chegar até a sete em regiões com altas temperaturas e luminosidade. No Nordeste brasileiro, por meio de uso de irrigação, é possível produzir o ano todo (MEZADRI et al., 2006).

Gomes et al. (2001), estudando a morfologia floral e a biologia reprodutiva de genótipos de aceroleira no período de um ano, observaram uma variação entre genótipos com relação ao número de dias em floração (22 a 34 dias) e dias de colheita (19 a 29 dias), sugerindo que há uma resposta particular de cada genótipo às condições climáticas. Carvalho (2003) observou uma queda acentuada de acerolas, principalmente no estádio inicial do desenvolvimento dos frutos, devido à ocorrência de baixas temperaturas, obtendo frutificação efetiva média de apenas 7,49 frutos/100 cachos florais.

Os frutos da aceroleira levam de 21 a 32 dias da antese à maturação e possuem tamanho que varia de 10 a 30 mm de diâmetro, de acordo com a cultivar e as condições de cultivo consideradas (JUNQUEIRA et al., 2004).

Os poucos trabalhos sobre fenologia da aceroleira (CARRINGTON; KING, 2002; CARVALHO, 2003; CARPENTIERE-PÍPOLO et al., 2008; GUEDES et al., 2011) são referências importantes, porém seus resultados nem sempre podem ser extrapolados de uma região para outra ou de uma cultivar para outra. Sendo assim, faz-se necessário o estudo dos padrões fenológicos das principais cultivares utilizadas nas regiões onde o cultivo dessa frutífera tem elevada importância econômica. No Estado de São Paulo, a região da Nova Alta Paulista apresenta a maior concentração de produção de acerola, destacando-se o município de Junqueirópolis, responsável por $63 \%$ da área plantada e maior produtor do Estado (LOURENZANI et al., 2009).

O objetivo deste trabalho foi estudar a fenologia e o crescimento dos frutos da aceroleira cv. Olivier em duas épocas do ano, em Junqueirópolis-SP.

\section{MATERIAL E MÉTODOS}

O trabalho foi conduzido em pomar comercial, na chácara Nossa Senhora Aparecida, município de Junqueirópolis-SP, latitude $21^{\circ} 18^{\prime} 00^{\prime \prime}$, longitude $51^{\circ} 15^{\prime} 00^{\prime \prime}$ e 420 metros de altitude. O clima do muni- cípio é subtropical úmido, Cwa, segundo a classificação de Köeppen, com inverno ameno e seco, e verão quente e chuvoso. A precipitação média é de 1.400 $\mathrm{mm}$ anuais e a temperatura média anual de $24^{\circ} \mathrm{C}$.

O pomar possui 400 plantas da cultivar Olivier distribuídas em um hectare, com espaçamento de 6 x $4 \mathrm{~m}$. O pomar foi implantado em 2003 e apresenta produtividade crescente.

O experimento foi implantado no ano agrícola de 2009/2010. Os dados foram coletados em duas épocas de produção, setembro e janeiro. Para a coleta dos dados meteorológicos, foram instalados próximo ao pomar um pluviômetro e um termômetro de máxima e mínima. Com o início da elevação das temperaturas, na segunda quinzena de agosto, as plantas foram irrigadas por sistema de gotejamento para estimular o início da floração e suportar o desenvolvimento dos frutos durante o período em que persistiu a estiagem. Com a chegada da estação chuvosa (outubro a março), irrigações esporádicas foram realizadas em casos de veranicos. As adubações e calagens foram feitas de acordo com as análises de solo. A adubação foi realizada no período que antecedeu a floração com aplicação de $0,5 \mathrm{~kg}$ de supersimples e $5 \mathrm{~kg}$ de esterco de galinha curtido por planta, na subcopa. Ao longo do ano, foram realizadas quatro aplicações de $300 \mathrm{~g}$ de NPK, na proporção de 20:05:20, além de pulverizações foliares com nitrogênio, cálcio e micronutrientes no início de cada florada. Os tratos culturais realizados foram poda de limpeza na entressafra, roçagem com trator na entrelinha e capina manual na linha.

Para cada época avaliada, foram marcados 40 botões florais em cada uma das dez plantas consideradas e que foram escolhidas por apresentarem mais homogeneidade entre si quanto ao fenótipo, totalizando 400 botões. Os botões foram marcados com linhas amarradas ao pedúnculo. Foi avaliada a duração, em dias, dos estádios fenológicos, o crescimento dos frutos e a porcentagem de queda das estruturas reprodutivas, a partir do número de botões marcados e, destes, quantos alcançaram o estádio de fruto maduro.

O ciclo reprodutivo foi dividido em sete estádios fenológicos: botão floral (0); flor (1); perda de pétalas (2); desenvolvimento inicial do fruto (3); fruto verde (4); maturação do fruto (5), e fruto maduro (6) (Figura 1). O estádio de maturação dos frutos foi determinado pela coloração externa, sendo considerados frutos verdes quando estes apresentavam coloração totalmente verde, frutos em maturação aqueles que apresentavam parte da casca avermelhada e os frutos maduros quando toda a superfície apresentava coloração vermelha. 
As avaliações foram realizadas diariamente até a completa maturação dos frutos, sendo feitas anotações sobre duração dos estádios fenológicos, queda das estruturas marcadas e tamanho dos frutos. Com o início do desenvolvimento dos frutos, foram feitas medições diárias do diâmetro dos mesmos até o estádio de maturação para a determinação da curva de crescimento nas diferentes épocas de avaliação. As medições foram realizadas por meio de paquímetro digital de $150 \mathrm{~mm}$.

O delineamento experimental utilizado foi o inteiramente casualizado, sendo que as épocas de avaliação (setembro/2009 e janeiro/2010) constituíram os tratamentos. As dez plantas analisadas foram as repetições, e os botões florais (400) corresponderam às parcelas experimentais. Os dados foram submetidos à análise de variância, pelo teste $\mathrm{F}$, e quando houve significância, as médias foram comparadas pelo teste de Tukey, a 5\% de probabilidade. A análise de variância foi efetuada em cada estádio e no ciclo completo dos meses de setembro e de janeiro para comparar a duração, em dias, nas duas épocas de avaliação. O programa estatístico utilizado foi o SIGMASTAT 3.5 .

\section{RESULTADOS E DISCUSSÃO}

As médias mensais de temperatura variaram de 18 a $32{ }^{\circ} \mathrm{C}$, no período de setembro a novembro, elevando-se nos meses seguintes, cujas médias de mínima e máxima foram de 21 e $35^{\circ} \mathrm{C}$, respectivamente. Os dados pluviométricos do período mostraram que houve precipitação durante todo o período, sendo que setembro foi o mês com menor índice de precipitação, $132 \mathrm{~mm}$, e o mês de novembro teve o mair índice pluviométrico, $298 \mathrm{~mm}$. O mês de janeiro destacouse pela distribuição das chuvas, sendo registrados 20 dias de precipitação ao longo do mês.

Na Tabela 1, são apresentados os dados de duração de cada estádio fenológico e de todo o ciclo reprodutivo da aceroleira. A duração média do ciclo da aceroleira 'Olivier', desde a emissão do botão floral até o amadurecimento do fruto, considerando as duas épocas analisadas, foi de 27,3 dias.

O estádio de botão (estádio 0 , Figura 1 ) durou 4,09 e 3,88 dias nos ciclos de setembro e janeiro, respectivamente. Dados de literatura relatam que decorrem sete dias do aparecimento do botão até a antese, embora haja tendência de redução nesse tempo para alguns genótipos durante os meses quentes e chuvosos (CARPENTIERE-PÍPOLO et al., 2008; GOMES et al., 2001). O número de dias decorridos da antese à formação do fruto (estádios 1 e 2, Figura
1) variou de 4,34 dias na época de janeiro e 5,66 dias em setembro. Resultados similares aos da presente pesquisa foram obtidos por Carpentiere-Pípolo et al. (2008) nas três cultivares de acerola avaliadas, nas condições do norte do Paraná, onde as variações foram de 3,4 a 6,3 dias, dependendo da cultivar e da época de avaliação. O período compreendido entre a abertura da flor até o amadurecimento do fruto (estádios 1 até 6 , Figura 1) variou de 20,87 a 25,76 dias nos meses de janeiro e setembro, respectivamente, sendo o valor médio de 23,81 dias, semelhante aos encontrados em literatura, de 21 a 32 dias da antese ao amadurecimento do fruto (GOMES et al., 2001). Nota-se que a duração dos estádios fenológicos foi maior na avaliação de setembro, com exceção dos estádios 3, 5 e 6, em que não houve diferenças significativas entre as épocas e, consequentemente, a duração do ciclo também foi maior nesta avaliação (Tabela 1). Este fato pode ser explicado pela ocorrência de temperaturas mais baixas neste período quando comparadas com o mês de janeiro, cuja temperatura média foi de $28^{\circ} \mathrm{C}, 2,5^{\circ} \mathrm{C}$ superior à média de setembro. Carpentiere-Pípolo et al. (2008) também observaram aumento no ciclo reprodutivo da aceroleira devido às temperaturas mais baixas e à menor luminosidade. Por ser uma planta de clima tropical, a aceroleira responde negativamente às quedas de temperatura, tanto na taxa de fixação de frutos como na duração do ciclo reprodutivo, conforme observado por Carvalho (2003).

O tempo compreendido entre o estádio de início do desenvolvimento de fruto verde até o de fruto maduro variou de 16,53 a 21,10 dias em janeiro e setembro, respectivamente, sendo estes valores próximos aos obtidos por Carpentiere-Pípolo et al. (2008), os quais variaram de 14,9 a 25,8 dias, de acordo com a cultivar de acerola considerada e a época de avaliação.

$\mathrm{Na}$ Tabela 2, são apresentados os dados de porcentagem de queda das estruturas reprodutivas dentro de cada estádio fenológico e de todo o ciclo reprodutivo da aceroleira. A análise de variância efetuada em cada estádio, nas duas épocas de avaliação e entre os estádios dentro de cada época, mostrou diferença significativa $(\mathrm{P}<0,001)$ para a interação das épocas e dos estádios. Comparando-se a porcentagem de queda das estruturas reprodutivas entre as épocas avaliadas, observa-se que houve diferença apenas nos estádios 0 (botão) e 3 (frutos no início do desenvolvimento). O alto índice de queda de botões $(20,5 \%)$ na safra de janeiro pode ser devido às fortes chuvas no início do mês, o que pode ter causado danos mecânicos a essas estruturas, resultando na queda das mesmas. Comparando-se 
o índice de queda das estruturas entre os estádios, o estádio 2 (perda de pétalas) apresentou alto índice em ambas as épocas de avaliação $(51,8 \%$ e $54 \%)$. Este fato já era esperado, visto que, após a antese, as flores não fecundadas tendem a cair. De forma geral, o estádio 0 (botão) para a época de setembro, o estádio 3 para janeiro e os estádios 1, 4, 5 e 6 para ambas as épocas apresentaram as menores porcentagens de queda.

Em relação ao total de estruturas abortadas, observou-se um abortamento de $70 \%$ para a safra de setembro e $88,6 \%$ para a safra de janeiro. Estes dados fornecem-nos a taxa de frutificação efetiva nas duas safras avaliadas, sendo que a taxa de frutificação em setembro corresponde a $30 \%$, e a de janeiro, a 11,4\%. Carpentiere-Pípolo et al. (2008) obtiveram taxas de frutificação similares às da presente pesquisa, variando de $10,7 \%$ a $32,7 \%$. No entanto, estes autores observaram menores taxas de frutificação na época de outubro/novembro, atribuídas às temperaturas mais baixas e à baixa luminosidade, diferindo dos resultados obtidos no presente trabalho, cujas menores taxas de frutificação foram observadas na época de janeiro, caracterizadas pela ocorrência de altas temperaturas.

$\mathrm{Na}$ literatura, não há relatos sobre o efeito de altas temperaturas no abortamento de flores de acerola. O que se observa, é que os picos de maior produção desta frutífera ocorrem justamente nos meses mais quentes, o que sugere que a baixa taxa de frutificação no ciclo de janeiro esteja relacionada com o alto índice pluviométrico, consequência da alta incidência de precipitações neste período.

Em relação ao desenvolvimento dos frutos, em ambas as avaliações, pode-se observar que o crescimento foi mais acentuado nos primeiros oito dias, tornando-se linear no restante do ciclo (Figura 2). Este resultado também foi encontrado por Carrington e King (2002) ao estudarem o desenvolvimento e o amadurecimento da acerola. Comparando-se as duas épocas de avaliação, nota-se que o período de desenvolvimento dos frutos foi mais curto no ciclo de janeiro, com o fruto alcançando a maturação em aproximadamente 18 dias. Já no ciclo de setembro, este período foi de, aproximadamente, 22 dias (Figura 2). Essa diferença pode ser explicada pela variação de temperatura entre as duas épocas, conforme descrito anteriormente para os dados de duração dos estádios fenológicos. O tamanho médio alcançado pelos frutos variou de $23 \mathrm{~mm}$ para a época de setembro a 28 $\mathrm{mm}$ para janeiro (Figura 2). Esta diferença pode ser explicada pelo menor número de frutos por planta na época de janeiro e também pela maior ocorrência de chuvas neste período.

TABELA 1- Médias e desvio-padrão da duração em dias dos estádios fenológicos e do ciclo total da aceroleira 'Olivier', nas duas épocas avaliadas (setembro/2009 e janeiro/2010). Junqueirópolis-SP.

\begin{tabular}{ccccc}
\hline & \multicolumn{2}{c}{ Épocas } & \multirow{2}{*}{ Média } & P \\
\cline { 2 - 3 } Estádios & Set/2009 & Jan/2010 & & \\
\hline $\mathbf{0}$ & $4,09 \pm 0,05 \mathrm{a}$ & $3,88 \pm 0,12 \mathrm{~b}$ & 3,985 & $<0,001$ \\
$\mathbf{1}$ & $1,92 \pm 0,09 \mathrm{a}$ & $1,67 \pm 0,12 \mathrm{~b}$ & 1,795 & $<0,001$ \\
$\mathbf{2}$ & $3,74 \pm 0,24 \mathrm{a}$ & $2,67 \pm 0,27 \mathrm{~b}$ & 3,205 & $<0,001$ \\
$\mathbf{3}$ & $3,19 \pm 0,27 \mathrm{a}$ & $3,44 \pm 0,86 \mathrm{a}$ & 3,315 & 0,387 \\
$\mathbf{4}$ & $13,85 \pm 0,50 \mathrm{a}$ & $10,04 \pm 0,82 \mathrm{~b}$ & 11,945 & $<0,001$ \\
$\mathbf{5}$ & $2,06 \pm 0,13 \mathrm{a}$ & $2,05 \pm 0,37 \mathrm{a}$ & 2,055 & 0,924 \\
$\mathbf{6}$ & $1,00 \pm 0,0 \mathrm{a}$ & $1,00 \pm 0,0 \mathrm{a}$ & 1,00 & 1,000 \\
\hline Total & $29,85 \pm 0,36 \mathrm{a}$ & $24,75 \pm 0,59 \mathrm{~b}$ & 27,30 & $<0,001$ \\
\hline
\end{tabular}

*Médias seguidas pela mesma letra na linha não diferiram estatisticamente entre si, pelo teste de Tukey $(\mathrm{P}<0,05)$

TABELA 2- Porcentagem de queda das estruturas reprodutivas em cada estádio fenológico e em todo o ciclo reprodutivo da aceroleira 'Olivier', nas duas épocas avaliadas (setembro/2009 e janeiro/2010). Junqueirópolis-SP.

\begin{tabular}{|c|c|c|c|c|c|c|c|c|}
\hline \multirow{2}{*}{ Épocas } & \multicolumn{7}{|c|}{ Estádios } & \multirow{2}{*}{ Total } \\
\hline & 0 & 1 & 2 & 3 & 4 & 5 & 6 & \\
\hline Set/2009 & $0,5 \mathrm{bC}$ & $3,8 \mathrm{aBC}$ & $51,8 \mathrm{aA}$ & $10,5 \mathrm{aB}$ & $2,5 \mathrm{aC}$ & $1,0 \mathrm{aC}$ & $0,0 \mathrm{aC}$ & 70,10 \\
\hline Jan/2010 & $20,5 \mathrm{aB}$ & $2,5 \mathrm{aC}$ & $54,0 \mathrm{aA}$ & $5,8 \mathrm{bC}$ & $4,8 \mathrm{aC}$ & $0,2 \mathrm{aC}$ & $0,8 \mathrm{aC}$ & 88,60 \\
\hline $\mathbf{P}$ & $<0,001$ & 0,600 & 0,345 & 0,046 & 0,345 & 0,753 & 0,753 & \\
\hline
\end{tabular}

Médias seguidas pela mesma letra minúscula na coluna e maiúscula na linha não diferiram estatisticamente entre si, pelo teste de Tukey $(\mathrm{P}<0,05)$. 


\section{1}

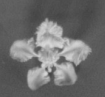

0

1

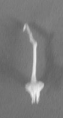

2

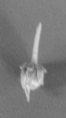

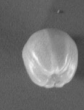

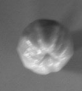

4

FIGURA 1- Estádios fenológicos adotados na avaliação da aceroleira 'Olivier': 0-botão floral; 1-flor; 2-perda de pétalas; 3-desenvolvimento inicial do fruto; 4-fruto verde; 5-maturação do fruto; 6-fruto maduro.

\section{Crescimento dos frutos}

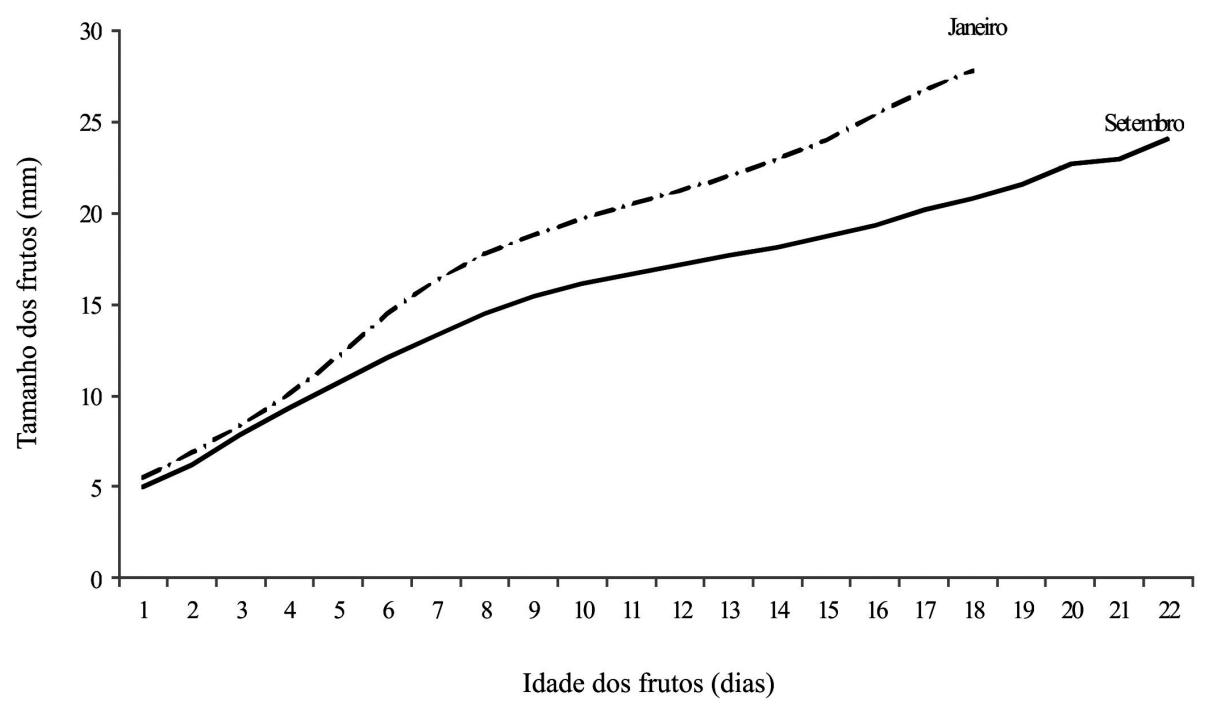

FIGURA 2- Curva de crescimento dos frutos da aceroleira 'Olivier' nas duas épocas de avaliação (setembro/2009 e janeiro/2010). Junqueirópolis-SP.

\section{CONCLUSÕES}

1- Há influência da temperatura na duração dos estádios fenológicos da aceroleira e, consequentemente, na duração do ciclo, sendo que o ciclo de janeiro é cinco dias mais curto que o de setembro.

2-A taxa de frutificação efetiva é de $30 \%$ em setembro e de $11,4 \%$ em janeiro, devido ao excesso de precipitação no mês de janeiro.

3-O maior índice de queda das estruturas marcadas dá-se no estádio de perda de pétalas, em ambas as avaliações.

4-Os frutos de ambas as épocas apresentam crescimento mais acentuado nos primeiros oito dias, mostrando-se linear no restante do ciclo.

\section{AGRADECIMENTO}

À Capes, pela concessão da bolsa de mestrado ao primeiro autor.

\section{REFERÊNCIAS}

CARPENTIERI-PÍPOLO, V.; NEVES, C. S. V. J.; BRUEL, D. C.; SOUZA, S. G. H. de; GARBÚGLIO, D. D. Frutificação e desenvolvimento de frutos de aceroleira no norte do Paraná. Ciência Rural, Santa Maria, v. 38, n. 7, p. 1871-1876, 2008.

CARRINGTON, C. M. S.; KING, R. A. G. Fruit development end ripening in Barbados Cherry, Malpighia emarginata DC. Scientia Horticulturae, Amsterdam, v. 92, p. 1-7, 2002. 
CARVALHO, R. I. N. de. Frutificação efetiva da aceroleira em condições outonais no município de Viamão-RS. Brasil. Revista Acadêmica: Ciências Agrárias e Ambientais, Curitiba, v. 1, n. 1, p. 23$26,2003$.

GOMES, J. E. ; PAVANI, M. do C. M. D. ; PERECIN, D. ; MARTINS, A. B. G. Morfologia floral e biologia reprodutiva de genótipos de aceroleira. Scientia Agrícola, Piracicaba, v. 58, n. 3, p. 519-523, 2001.

GUEDES, R. da S.; ZANELLA, F. C. V.; MARTINS, C. F.; SCHLINDWEIN, C. Déficit de polinização da aceroleira no período seco, no semiárido paraibano. Revista Brasileira de Fruticultura, Jaboticabal, v. 33, n. 2, p. 465-471, 2011.

JUNQUEIRA, K. P.; PIO, R.; VALE, M. R. do; RAMOS, J.D. Cultura da acerola. Lavras: UFLA, 2004. 27 p.
LOURENZANI, A.E.B.S.; LOURENZANI, W.L.; PINTO, L.B.; OGASAWARA, K.R. A cadeia produtiva da acerola na região Nova Alta Paulista. In: CONGRESSO DA SOCIEDADE BRASILEIRA DE ECONOMIA, ADMINISTRAÇÃO E SOCIOLOGIA RURAL, 47., Porto Alegre. Anais... Brasília: SOBER, 2009. p.1-16. Disponível em: <http:// www.sober.org.br/palestra/13/1050.pdf > . Acesso em: 13 jan. 2012.

MEZADRI, T.; FERNANDES-PACHÓN, M. S.; VILLANÕ, D.; GARCÍA-PARRILLA, M. C.; TRONCOSO, A. M. El fruto de la acerola: composición y posibles usos alimenticios. Alan, Caracas, v. 26, n. 2, p. 101-109, 2006.

PORTAL DO AGRONEGÓCIO. Produção de frutas ganha força no Brasil. Viçosa, 2008. Disponível em: <http://www.portaldoagronegocio.com.br/ conteudo.php?id=5982>. Acesso em: 16 mar. 2011 . 